\title{
A Case Study of the Communication Pattern and Participation in Life of a 51-Year Aphasic Adult in Natural Setting
}

\author{
Ojinga Gideon Omiunu \\ Africa Regional Centre for Information Science, University of Ibadan, Unicorn Academics and Organisation \\ Developmental Research Centre, Ibadan, Nigeria \\ Email: ohiojingao@yahoo.com, omiunuojingag@gmail.com
}

Received 10 April 2014; revised 26 May 2014; accepted 6 June 2014

Copyright (C) 2014 by author and OALib.

This work is licensed under the Creative Commons Attribution International License (CC BY). http://creativecommons.org/licenses/by/4.0/

(c) (i) Open Access

\begin{abstract}
Aphasia is an impairment of language ability which results in a language disorder. Aphasic (Aged) patients are believed to have bad communication pattern and also low participation in life. This study examined communication use and participation in life for aphasic adults in natural setting. The study employed the case study research design which involves the use of a 51-year-old aphasic patient. The study area was Ibadan, Oyo State, Nigeria. The purposive and convenience sampling method was used, which include the purposive selection of the aphasic adult patient. Two major instruments used for this study are interview and discussion. Data obtained were analysed qualitatively. The result showed that, the aphasic patient has major deviant problems in the substitution of sound /'p'/ for /'b'/ and also making incomplete statements, which produce a confusion between the aphasic patient and the listeners. In conclusion, the aged aphasic patient under investigation does differ from the existing ones, specifically, expressive aphasia as there was slight difference in his communication patterns and life participation seems also slightly different from that of the aged non-aphasic. In addition, his aphasic condition is not as high as others born with it.
\end{abstract}

\section{Keywords}

Aphasia, Participation in Life, Communication Pattern, Aphasic Patients

\section{Introduction}

It is well recognized that difficulties in body functions and structures ("Impairments") are the most studied outcomes in communication disorders [1] [2]. Such impairment includes: measures of speech, language, voice, and 
fluency including measures of articulatory accuracy, grammatical complexity of language, physiological functioning of the vocal folds, and a number of influences.

Aphasia is an impairment of language ability which results in a language disorder and ranges from having difficulty remembering words to being completely unable to speak, read, or write. Aphasia disorders usually develop quickly as a result of head injury or stroke, but can develop slowly from a brain tumor, infection, or dementia, or can be a learning disability such as dysnomia [3]. The area and extent of brain damage determine the type of aphasia and its symptoms. Aphasia types include Broca's aphasia, non-fluent aphasia, motor aphasia, expressive aphasia, receptive aphasia, global aphasia and many others. Medical evaluations for the disorder range from clinical screenings by a neurologist to extensive tests by a Speech Language Pathologist.

Although, some aphasic patients can recover through the help of Speech Language Pathologists, however, the rehabilitation can take two or more years and is most effective when begun quickly. Only a small minority will recover without therapy, such as those suffering a mini-stroke. Patients with a learning disorder aphasia such as dysnomia can learn coping skills, but cannot recover abilities that are congenitally limited [4]. Improvement varies widely, depending on the aphasia's cause, type and severity, and also depending on the patient's age, health, motivation, handedness, and educational level.

Communication is a lifelong learning process beginning at birth and is made in different ways like listening, speaking, gesturing, reading, and writing. Communication abilities help one to learn, form social relationships, express feelings, and participate in everyday life activities [5]. Some individuals, due to cognitive and/or physical impairments, may have difficulty expressing themselves clearly or understanding what is being said to them. Ensuring effective use of communication and participation in life for adults with aphasia in their natural settings may require broader and more extensive interventions than previously envisioned or actively managed by speech language pathologists [6]. Acquired brain damage unquestionably diminishes the extent to which adults with aphasia make use of communication and participation in daily life. But optimal management of aphasia extends beyond an anatomic-physiologic basis of dysfunction or even concentrated efforts to remediate linguistic or communication disabilities. Past failures to achieve a solution to this problem may be more because of what is absent from aphasia treatment than the improper or incomplete repair or management of what currently is treated.

Traditionally, assessment of aphasic patients has focused on testing their linguistic abilities by using "metalinguistic tasks whose aim is to elicit expected standard responses, not to test creative uses of communication", Feyereisen [7]. Some aphasic individuals demonstrate the ability to communicate much better than others, speak/ understand. Although this proposition might seem somewhat paradoxical as Feyereisen suggests [7]. A Life Participation Approach focuses directly on life participation of Aphasic patients. There is no expectation that such impairment would decrease or increase functional skill. Although therapy might include activities at the "body" and "individual" levels, these must explicitly bridge to define life participation goals [8].

There are perceived participation and communication problems in participation in life situations with aphasic patients [9]. This is because aphasic patients have language disorder and could find it difficult to excel in academic performance because they are unable to remember words, unable to speak, read, write, or even communicate. This could however cause isolation of individuals with aphasia and can also result in stigmatization from non-aphasic individuals.

This implies that addressing participation and problems with participation in the rehabilitation of persons with aphasia may lead to an enhanced life satisfaction. To this end, this study aimed at examining communication use and participation in life for aphasic adults in natural setting.

\section{Theoretical Review}

Although, aphasic patients seem to be the easiest to rehabilitate as these patients can understand the method used in a given rehabilitation technique, or at least the directions to utilize the technique. Unfortunately, rehabilitation of aphasia continues to pose a significant challenge [10] and there have been scanty success in rehabilitation trials in aphasic patient.

There are needs to assess before treating aphasic patients, and after assessment, what should come next for a patient found to have aphasia is based on their assessment. Altschuler et al. state that often it is observed that a basis for therapy is drawn out from the observation made on a given patient [10]. 


\section{Literature Review}

There is a huge variation among patients with the same diagnosis, and aphasia can be highly selective [11]. Aphasia can be divided into three categories: fluent, non-fluent and "pure” aphasias [11]. In addition, aphasia can also be classified as: receptive, intermediate and expressive. Fluent aphasia include Wernicke’s aphasia, Transcortical sensory aphasia, Conduction aphasia, Anomic aphasia. Nonfluent aphasia, also called expressive aphasia are difficulties in articulating, but in most cases there is relatively good auditory verbal comprehension. Examples of nonfluent aphasia are Broca's aphasia, Transcortical motor aphasia, Global aphasia. Pure aphasia are selective impairments in reading, writing, or the recognition of words. These disorders may be quite selective. For example, a person is able to read but not write, or is able to write but not read. Examples of pure aphasia are Pure alexia, Agraphia, Pure word deafness.

Aphasia can also be divided into primary and secondary aphasia [12]. Primary aphasia is due to problems with language-processing mechanisms. Secondary aphasia is the result of other problems, like memory impairments, attention disorders, or perceptual problems.

Aphasic patients' ability to communicate their thoughts, needs and wishes is significantly better, sometimes approaching normal, using non-verbal means such as actions, movements, props, gestures, facial expressions and affection, than verbally. However, Altschuler et al. suggested that standard speech therapy per se will not be used for Wernicke aphasic patients, but instead place patients in real or simulated situations important to them and have them work on using non-verbal means to successfully communicate [13].

Unprecedented changes resulting from both internal and external pressures, are influencing how speech-language pathologists (SLPs) carry out their jobs [14].

According to Roberta et al., internal influences which include a growing interest in treatments that produce meaningful real life outcomes leading to enhanced quality of life, while external influences include the influence by disability rights activists which encourage adjustments in philosophy and treatment, and by consumers frustrated by unmet needs and unfulfilled goals [14]. The life participation approach to aphasia (LPAA) is a consumer-driven service-delivery approach that supports individuals with aphasia in achieving their immediate and longer term life goals. It focuses on re-engagement in life, beginning with initial assessment and intervention, and continuing, after hospital discharge, until the patient no longer need communication support [14]. In addition, LPAA places the life concerns of those affected by aphasia at the center of all decision making.

\section{Research Methods}

The study adopted the case study research design which involved the use of an aphasic adult patient of age 51 . Although, the study area is Ibadan, Oyo State, Nigeria, however, the study majors on only one aphasic patient. The purposive and convenience sampling method was used, which include the purposive selection of the aphasic adult patient. The uniqueness of this study is that this 51 years old aphasic patient is a Civil Servant in the Nigerian Custom Service, Federal Republic of Nigeria. Two major instruments used for this study included interview and discussion with respondent and observations were also made by the researcher during conversation. This study narrated and described the real life experience of an aphasic patient in communication and participation in life in the natural setting.

Also, this aphasic patient was not born one, but became an aphasic patient after an accident which occurred at age 41 . He was however rushed to the hospital, after much intensive care, he survived and became an aphasic patient. This implies that he never had any neurological or Alzheimer history. The method of data collection involved a one-on-one interaction with the aphasic patient and also necessary observations were made on aphasic patient's natural life experience. The one-on-one questions included a structured interview guide which involves the use of relative dialogue with the aphasic adult patient with regards to his personal life, communication and social life.

The collection of data involved a one-week activity. First, the researcher was introduced to the aphasic patient, second data collection began after rapport has been established with the aphasic adult patient to put his mind at ease and feel free to participate in the activity. Finally, data obtained were analysed qualitatively.

\section{Result and Discussions of Findings}

\subsection{Phonological Errors in the Aphasic Respondent}

Although, aphasic patients have different phonological differences, however, these differences occur in dimen- 
sions and grades. In the case of the respondent used for this study, the only phonological error observed is only substitution. For instance, in the pronounciation of "proud", which is "/praud/", the aphasic patient, pronounced it as "broud" which is now written as "/braud/". Another substitution pronounciation error made by the aphasic patients include the pronunciation of "hypertension", which is phonologically pronounced as "/harpər'ten $\int \mathrm{n} /$ " was pronounced by the aphasic patient as hybertension, which is phonologically pronounced as "/harbər'ten $\int \mathrm{n} /$ ".

From the two pronunciations, it is observed that, the aphasic patient, substituted the sound /"p"/ for /"b"/, which is a speech defect. There was however accurate pronounciation of other sounds. The word "orange" which was phonologically pronounced as "/s:rnndz/" was rightly pronounced by the aphasic patient as "orange", without any omission or substitution. This further shows that, the aphasic patient's speech difficulty in this study is not high as he could pronounce most words effectively without omission of some sounds, but however has problem with the pronunciation of sound /"p"/ in any word. The problem of the pronunciation of sound /"p"/ is even more compounded when letter /"p"/ occurs twice in a word like perpetual. Also, to this aphasic patient, there is no difference between the letter /"p"/ and sound /“b”/, as the letter /“p"/ was pronounced as letter /"b"/.

This buttresses Eadie [15] and Threats [16] that impairments in aphasic patients include measures of speech, language, voice, and fluency, measures of articulatory accuracy, grammatical complexity of language, physiological functioning of the vocal folds, and number of disfluencies. Although, the stage of the aphasic patient used in this study is not high as he could still communicate effectively, relate well in life issues, however, has grammatical complexity. Also, the findings buttress Kolb and Whishaw [17] who stated that, there is a huge variation among patients with the aphasia and this kind of aphasia is a secondary type. According to Thomson Slvievert.com [18] who stated that, aphasia can be divided into primary and secondary aphasia. This is because secondary aphasia is the result of problems, like memory impairments, attention disorders, or perceptual problems.

\subsection{Substitution of Sounds in the Aphasic Patients Pronunciation}

The study paid more attention to the aphasic patient's pronunciation, because the patient has major problems on the substitution of sound /"p"/ for /"b"/. The pronunciation of the aphasic patient used for this study showed a deviant form from the actual pronunciation most especially in words which has the sound /"p"/. Table 1 provides both the actual pronunciations of some selected words used in the conversation with the aphasic patient and the deviant form of his pronunciation.

The deviant form of the aphasic patient pronunciation showing the substitution of sound /"p"/ for /"b"/ is presented in Table 1. The table shows that, the aphasic patient used for this study has the pronunciation problem of words with sound /"p"/, which is substituted with the sound /"b"/. This is however different from other aphasic patients as most of them have more speech defect than this.

\subsection{Omission and Insertion}

Although, the aphasic patient used in this study has speech pronunciation problem, there was neither error of omission nor of insertion, as the pronunciation of other words of the aphasic patient used for this study were

Table 1. Deviant form of Aphasic patient pronunciation.

\begin{tabular}{|c|c|c|c|c|}
\hline \multicolumn{3}{|c|}{ Actual form } & \multicolumn{2}{|c|}{ Deviant form } \\
\hline & Words & Phonological Pronunciation & Words & Phonological Pronunciation \\
\hline 1 & Spiritual & /spirituəl/ & Sbiritual & /sbirituəl/ \\
\hline 2 & Perpetual & /pər’petyøəl/ & Berbetual & /bər’betyoəl/ \\
\hline 3 & Proud & /praod/ & Broud & /bravd/ \\
\hline 4 & Responded & /rı’spa:ndid/ & Resbonded & /rı’sba:ndid/ \\
\hline 5 & Hypertension & /haipər'ten $\int \mathrm{n}$ / & Hybertension & /harbər'ten $\int \mathrm{n}$ / \\
\hline 6 & Police & /pə’li:s/ & Bolice & /pə’li:s/ \\
\hline 7 & Pray & /prei/ & Bray & /Brei/ \\
\hline
\end{tabular}


accurate. Thus, no speech defect to this effect is detected. This shows another kind of aphasia exists. The findings adds more to the findings of Kolb and Whishaw [17] and Altschuler et al. [13], who presented other major kinds of aphasia, however different from the aphasia in this study.

The aphasic patient's pronunciation is presented in Table 2. The result showed no error of omission and also did not show any insertion of any sound into words as the words provided by the researcher for the aphasic patient to pronounce were pronounced accurately. This shows that the aphasic patient did not show word defect in respect to these words.

\subsection{Speech Comprehension in Conversation}

The aphasic patient was interviewed and there were speech conversation between the patient and the researcher. Also observations were made as the conversation went on and speech utterances were also noted if there were errors in the aphasic patient conversation. The conversation involved during the interview, involves asking the aphasic patient some question and answers provided by the patient were recorded and transcribed.

\subsection{Conversation between the Researcher and the Aphasic Patient I}

In the conversation, "R", represents the researcher or interviewer while "p" represents the aphasic patient in the conversation.

Table 2. Aphasic patient’s pronunciation.

\begin{tabular}{|c|c|c|c|c|}
\hline \multirow{2}{*}{$\mathbf{s} / \mathbf{n}$} & \multicolumn{2}{|c|}{ Actual Form } & \multicolumn{2}{|c|}{ Aphasic Patient's Pronunciation } \\
\hline & Words & Pronunciation & Words & Phonological Pronunciation \\
\hline 1 & Injection & /In’dzek $\int \mathrm{n} /$ & Injection & /In’dzek/n/ \\
\hline 2 & Orange & /’o:rındz/ & Orange & /’o:rindz/ \\
\hline 3 & Exactly & /ıg'zæktlı/ & Exactly & /Ig'zæktlı/ \\
\hline 4 & Lemon & /'lemən/ & Lemon & /’lemən/ \\
\hline 5 & Environment & /m’varrənmənt/ & Environment & /In’varrənmənt/ \\
\hline 6 & Natural & /nætfrəl/ & Natural & /nætfrəl/ \\
\hline 7 & Standard & /'stændərd/ & Standard & /'stændərd/ \\
\hline 8 & X-ray & /'eksrei/ & X-ray & /'eksrei/ \\
\hline 9 & Should & /Jud/ & Should & /sod/ \\
\hline 10 & Fluently & /'flu:əntli/ & Fluently & /'flu:əntli// \\
\hline 11 & Exercise & /'eksərsaiz/ & Exercise & /'eksərsarz/ \\
\hline 12 & Arrange & /ə’reIndz/ & Arrange & /a'reindz/ \\
\hline 13 & Intellect & /'Intəlekt/ & Intellect & /'Intəlekt/ \\
\hline 14 & Tongue & $/ \mathrm{t} \wedge \mathrm{y} /$ & Tongue & $/ \mathrm{t} \wedge \mathrm{y} /$ \\
\hline 15 & Arrested & /a’restid/ & Arrested & /a’restid/ \\
\hline 16 & Cannot & /'kæna:t/ & Cannot & /'kæna:t/ \\
\hline 17 & Yesterday & /'jestərder]/ & Yesterday & /'jestərdeI]/ \\
\hline 18 & English & /'InglII/ & English & /'Inglif// \\
\hline 19 & Meat & /mi:t/ & Meat & /mi:t/ \\
\hline 20 & Anoint & /On:int/ & Anoint & /On:int/ \\
\hline
\end{tabular}




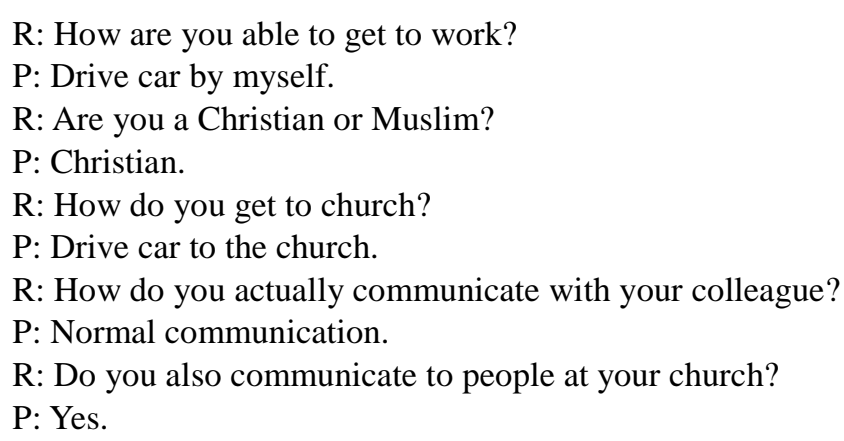

The above conversation was done and carried out by the researcher with the aphasic patient. From the conversation, it was obvious that the patient could link conversations together. Accurate answers were also provided by the aphasic patient of himself. It was however noted that he somehow has a conversation problem which has made conversation with colleague different from the conversation with non-aphasic patient. The conversation also shows that the patient could however do work by himself, drive car by himself to work and church. The conversation also shows that the patient had understanding of all conversations, and could comprehend the questions asked by the researcher, providing accurate answers or responses to the questions. Nevertheless, there were signs and evidence of incomplete statement. For example: drive car by myself.

\subsection{Conversation between the Researcher and the Aphasic Patient II}

R: How do you manage work stress that it will not affect your life?

$\mathrm{P}$ : My boss gives me enough time to rest before coming to work.

$\mathrm{R}$ : What are the aspects of life you find difficult to perform?

$\mathrm{P}$ : I find it difficult in using my right hand carrying heavy object.

R: How do you manage your daily life?

$\mathrm{P}$ : As normal like other people.

R: Do you find it difficult to express yourself, and feeling to people?

P: No.

R: How do you feel when people could not understand you?

P: I feel slighted.

Conversation II shows also a perfect conversation between the researcher and aphasic patient. The conversation showed that the boss at work gives the patient time as he understands the problem. The patient stated that, he had difficulty using his right hand to carry heavy object. Coping with life issues demands understanding on those with whom aphasic patients come into contact. Although, in the case of the aphasic patient used for this study, he actually didn't find it difficult making conversation with people and expressing himself to people. However, there is the demand for individuals relating with the aphasic patient for understanding. Nevertheless, there might be few occasion when such understanding is absent, this however makes the aphasic patient feel bad. This might be because; he assumes he should be understood, despite his aphasic condition.

This buttresses the findings of Reinhartsen \& Pierce [19] that, communication abilities help one to learn, form social relationships, express feelings, and participate in everyday life activities, however where this is absent, there might not be effective communication. This may be the reason why the aphasic patient used for this study feels upset when such communication are not understood by the recipient, because it might retard everyday life activities. Nevertheless, life activities for this aphasic patient is not distorted as he could still perform most activities by himself.

However, responses of the aphasic patient seem so blunt and sharp for instance when he was asked:

R: How are you able to get to work?

P: Drive car by myself.

R: Are you a Christian or Muslim?

P: Christian.

R: How do you get to church?

$\mathrm{P}$ : Drive car to the church. 


\subsection{Grammatical Analysis of Aphasic Patient Speech}

The grammatical analysis of the aphasic patient speech is presented.

R: How are you able to get to work?-Question one

$\mathrm{P}$ : Drive car by myself.-Response one

R: How do you get to the church?-Question Two

P: Drive car to the church.-Response Two

From the conversation between the researcher and the aphasic patient above, in response one, the statement: "Drive car by myself”, does not portray a complete and correct statement. This is because, reflexive pronouns like, myself, yourself, himself are often used to refer to subjects. For instance,

"I hurt myself."

The word "myself" which is a reflexive pronoun should have an antecedent "I". Although, "myself" in response one of the aphasic patient shows that the statement has a subject, however, the absence of "I" which is suppose to present the subject of the sentence makes the statement incorrect, because the word "myself" should have been referring to the word "I".

In Response two, the statement: "Drive car to the church" is also an incomplete statement as it does not have a subject. It however, has an object and a predicate. The statement is not necessarily telling who drove the car to the church. The absence of "I" makes the sentence incorrect and incomplete.

These however show that, it takes the listener or hearer of this aphasic patient to understand, and fill in the gap to interpret and relate such statements into real life circumstances to provide accurate response which the aphasic patient meant. Nevertheless, there might be some occasions when there could be misunderstanding between the aphasic patient and the listeners or hearers. At these periods, the aphasic patient is always bordered. This was deduced from his response when asked, how he felt when people don't understand him. His response was again sharp, blunt and straight forward.

\section{Conclusion}

In conclusion, the aphasic patient under investigation does differ from the existing ones, specifically, expressive aphasia as there was slight difference in his communication patterns and life participation seems also slightly different from that of the non-aphasic. The patient condition was not a chronic one, as he could perform real life activities as non aphasic individual. In addition, his aphasic condition is not as high as others born with it. Beside, the patient's condition was found to be phonetically inclined towards bilabial plosives. That is, it had so much to do with the articulation of the plosive sounds. In other words, in the course of articulation, the patient was found to have replaced the voiceless bilabial plosive sound /P/ with the voiced bilabial plosive. Nevertheless, life participation of the aphasic patient was very much inclined with some level of accuracy as contrary to those chronic ones who needed someone to support them in their life participation activities.

\section{References}

[1] Eadie, T.L. (2001) The ICIDH-2: Theoretical and Clinical Implications for Speech-Language Pathology. Journal of Speech-Language Pathology and Audiology, 25, 181-200.

[2] Threats, T.T. (2000) The World Health Organization's Revised Classification: What Does It Mean for Speech-Language Pathology? Journal of Medical Speech-Language Pathology, 8, 13-18.

[3] Masdeu, J.C. (2000) Aphasia. Archives of Neurology, 57, 892-895. http://dx.doi.org/10.1001/archneur.57.6.892

[4] Mayo Clinic Staff (2011) Aphasia: Treatments and Drugs. http://www.mayoclinic.com/health/aphasia/DS00685/DSECTION=treatments-and-drugs

[5] Reinhartsen, D. and Pierce, P. (1998) Developing Communication Abilities.

[6] Lyon, J.G. (1992) Communication Use and Participation in Life for Adults with Aphasia in Natural Settings. American Journal of Speech-Language Pathology, 1, 7-14.

[7] Feyereisen, P. (1991) Communicative Behaviour in Aphasia. Aphasiology, 5, 323-333. http://dx.doi.org/10.1080/02687039108248533

[8] Chapey, R., Duchan, J.F., Elman, R.J., Garcia, L.J., Kagan, A., Lyon, J. and Mackie, N.S. (2012) Life Participation Approach to Aphasia: A Statement of Values for the Future. Life Participation Approach to Aphasia Project Group.

[9] Lund, M.L. and Lexell, J. (2009) Relationship between Participation in Life Situations and Life Satisfaction in Persons 
with Late Effects of Polio. US National Library of Medicine National Institutes of Health, Bethesda.

[10] Altschuler, E.L., Multari, A., Hirstein, W. and Ramachandran, V.S. (2006) Situational Therapy for Wernicke’s Aphasia. Medical Hypotheses, 67, 713-716. http://dx.doi.org/10.1016/j.mehy.2005.10.035

[11] Kolb, B. and Whishaw, I.Q. (2003) Fundamentals of Human Neuropsychology. Worth Publishers, New York, 502, 505, 511.

[12] Thomson Healthcare, Inc. (2011) Health Reference Center Academic. Retrieved 26 Feb. (2012). Template: “Aphasia”. CareNotes.

[13] Altschuler, E.L., Multari, A., Hirstein, W. and Ramachandran, V.S. (2006) Situational Therapy for Wernicke’s Aphasia. Medical Hypotheses, 67, 713-716. http://dx.doi.org/10.1016/j.mehy.2005.10.035

[14] Elman, R.J. (2000) Language Disorders in Adults Grand Rounds: Life Participation Approaches to Aphasia. http://www.aphasiacenter.net/asha2000_lpaa_handouts.html

[15] Eadie, T.L. (2001) The ICIDH-2: Theoretical and Clinical Implications for Speech-Language Pathology. Journal of Speech-Language Pathology and Audiology, 25, 181-200.

[16] Threats, T.T. (2000) The World Health Organization's Revised Classification: What Does It Mean for Speech-Language Pathology? Journal of Medical Speech-Language Pathology, 8, 13-18.

[17] Kolb, B. and Whishaw, I.Q. (2003) Fundamentals of Human Neuropsychology. 6th Edition, Worth Publishers, New York, 502, 505, 511.

[18] Slvievert.com (2010). Aphasia. http://webcache.googleusercontent.com/search?q=cache:eJ-VsBr99q8J:http://sylvievert.com/ReadingMaterial/Aphasia. pdf\%2BAphasia+can+also+be+divided+into+primary+and+secondary+aphasia\&hl=en-NG\&gbv=2\&\&ct=clnk

[19] Reinhartsen, D. and Pierce, P. (1998) Developing Communication Abilities. In Pierce, P., Ed., Baby Power: A Guide for Families for Using Assistive Technology With Their Infants and Toddlers. NC Department of Health and Human Services, Raleigh, 1994. 